\title{
Thematic elements of the postgraduate NP residency year and transition to the primary care provider role in a Federally Qualified Health Center
}

\author{
Margaret Flinter ${ }^{1}$, Ann Marie Hart ${ }^{* 2}$ \\ ${ }^{1}$ Community Health Center, Middletown, Connecticut, United States \\ ${ }^{2}$ School of Nursing, University of Wyoming, Laramie, Wyoming, United States
}

Received: June 28, 2016

DOI: $10.5430 /$ jnep.v7n1p95
Accepted: July 21, 2016

Online Published: August 30, 2016

\begin{abstract}
Background/Objective: Although the literature supports that nurse practitioners provide quality primary care resulting in excellent outcomes, the transition from nurse pracitioner education to practice is often difficult. Postgraduate residency programs have been suggested to help new nurse practitioners successfully transition, and studies indicate that most new nurse practitioners are interested in postgraduate residencies; however, little is known about how residencies facilitate transitioning. We sought to understand the experience of nurse practitioners in a residency program in the United States and how the program facilitated their transition to the role of primary care provider.

Methods: Reflective journals of 24 Residents who completed the first primary care nurse practitioner residency in the United States were analyzed using Content Analysis.

Results: Four to nine themes for each month and one theme for each yearly quarter were identified. Residents went from feeling shocked and overwhelmed to becoming confident, competent primary care providers, committed to underserved populations. Transitioning conditions (e.g., on-call experience) and specific facilitators (e.g., engaged preceptors) and stressors (e.g., managing chronic pain and reqests for opioids) that impacted their transition were also identified.

Conclusions: The findings are significant as the United States addresses the shortage of primary care providers and models for postgraduate residencies and fellowships for nurse practitioners and other advanced practice registerered nurses emerge. The findings also represent the first qualitative data that reflect the experience of nurse practitioner Residents and provide rich insight into the overall experience of a one year residency, as well as facilitating and stressful factors. Organizations that are developing or refining nurse practitioner residencies or fellowships should consider these findings and discuss ways to address them with both nurse practitioner Residents and preceptors, as well as program and organizational leadership.
\end{abstract}

Key Words: Nurse practitioners, Primary care, Residency, Transition to practice, Underserved populations, Clinical workforce development

\section{INTRODUCTION}

In the 50-year history of nurse practitioners (NPs), considerable focus has been placed on the role of NPs, the type and quality of care they deliver, and the experience of NPs as they transition from academic preparation into practice. Multiple studies confirm the high quality and safety of NP-delivered States.

*Correspondence: Ann Marie Hart; Email: annmhart@uwyo.edu; Address: School of Nursing, University of Wyoming, Laramie, Wyoming, United 
care $^{[1-3]}$ but suggest a difficult transition for new NPs as they move from the academic to service delivery setting. ${ }^{[4-6]}$ Postgraduate training programs such as NP residencies and fellowships have been suggested as a logical next step in providing depth and intensity of clinical training to give new NPs an opportunity to develop greater confidence and competence in their practice as primary care providers (PCPs). ${ }^{[7-9]}$ Moreover, in their report on the "Future of Nursing", the Institute of Medicine (IOM) ${ }^{[10]}$ recommended residency programs for all nurses upon completion of prelicensure and advanced practice programs and when they are transitioning to new practice areas.

\subsection{Postgraduate NP residency programs}

In 2007, the leaders of a large federally qualified health center (FQHC) in Connecticut, United States (U.S.), Community Health Center, Inc. (CHCI), developed a conceptual model for FQHC-based postgraduate residency training for new NPs committed to practice careers as PCPs. ${ }^{[1]}$ Their intent was to design an intensive postgraduate training experience that would support new NPs, committed to practice careers as primary care providers in the safety net setting, in the development of confidence, competence, and mastery in their role as a primary care provider. CHCI launched the U.S.'s first formal NP residency program for family nurse practitioners (FNPs) with an initial cohort of four. With the completion of the 2015-16 cohort, a total of 56 FNPs have completed the CHCI program, with the cohort size gradually increasing to 10 per year. In the years since CHCI started the NP residency program, postgraduate training programs for new NPs, designated by their organizations as either residency or fellowship programs, have been developed in primary care, as well as specialty areas in other FQHCs, ${ }^{[9,12,13]}$ the U.S. Veterans Affairs (VA) systems, ${ }^{[14,15]}$ hospital/health systems, ${ }^{[16-18]}$ and private medical groups. ${ }^{[19,20]}$

The model developed by CHCI is based upon both its organizational expertise in primary care and its decades of experience with new NPs, as well its study of other health professions' postgraduate training models. It is a highly structured, 12-month curriculum based on several core components: intensive preceptored clinical sessions as a PCP developing a panel of patients, formal didactic educational sessions built around the needs of the population of focus in FQHCs, specialty and procedural training, and training to a high performance model of care delivery. The residency application is open to NPs who have completed the Master's or Doctor of Nursing Practice (DNP) degree within the past 18 months, are or will be board certified in their specialty area by the start date of the program, and have an expressed intent to practice as a PCP in a safety net setting such as a community health center. The application includes letters of reference from academic and clinical colleagues, as well as personal essays. Additionally, all finalists are interviewed in person by a team of program and organizational leaders. The one year program is a full time, salaried position with the salary set at about $60 \%$ of the current community norm for new NPs.

CHCI's NP residency program begins with an intensive four week orientation to the community (service area), target population, population of focus, and practice site. It includes an intensive orientation to the organization itself, with training to the organization's model of integrated, team-based care; electronic health records and technology; and data-driven quality improvement. Following the four week orientation, the post-graduate NP Residents (hereafter referred to as "Residents") are assigned in teams of two, to one of five different primary care sites throughout the service area, where they are embedded in a clinical pod as part of a primary care team including medical assistants (MAs), a registered nurse $(\mathrm{RN})$ and a behavioralist (e.g., Licensed Clinical Social Worker, psychologist), along with PCPs, who may be NPs, physicians, or physician assistants (PAs). As board certified, licensed independent providers, the Residents are enrolled with all payors as PCPs and a developing panel of patients is attributed to them.

Forty percent of the Residents' time is devoted to building their patient panel, made up primarily of patients who are presenting to $\mathrm{CHCI}$ as new patients and represent a full range of age, complexity, and acuity. An expert CHCI faculty member, either a NP, a physician, or a PA, are assigned to a team of two Residents during each precepted session to consult, teach, support, and guide them. The remainder of the Residents' time is devoted to specialty training, didactic education, and independent clinic sessions during which an experienced PCP is available for consultation, but not exclusively assigned to precepting. Ten specialty rotations are incorporated into the schedule and were selected for their relevance to primary care, particular to the FQHC model of comprehensive care across the life span, including prenatal/women's health, adult and child psychiatry, dermatology and orthopedics, chronic pain management, Hepatitis $\mathrm{C}$ and HIV management, newborn nursery, and pediatrics. The didactic lectures and discussions, including case presentations, are built on both the common and the uncommon challenges encountered in the clinical setting of FQHCs, as well as other primary care settings where the social determinants of health exert strong impact.

From its inception, the residency program has included a strong evaluation component including bi-directional evalua- 
tions between preceptors and NP Residents, self-assessment of competency using a standard tool, and evaluation of the overall program by the NP Residents. One central element of the evaluation has been the use of weekly self-reflection in the context of real-time communication between the Residents and the program leaders. Using a "reflective journal" approach, the Residents submit a written journal entry each week, reflecting on their experience during the prior week. The journals are read and responded to by a designated NP program leader. To our knowledge, this is the only real-time data of the week-by-week experience of new NPs as they undergo the transition from new graduate NP to practice, and in this case, the only real-time data of this experience in the context of a highly organized and structured postgraduate residency program. Thus, this study focused on this element of the evaluation program.

\subsection{Background on FQHCs}

Community Health Centers, now more commonly known as FQHCs, also have a 50-year history in the U.S., with the first health centers launched in Mound Bayou, Mississippi and Boston, Massachusetts, as an outgrowth of the civil rights movement and the war on poverty. ${ }^{[21-23]}$ Although the long and storied history of the health center movement is beyond the scope of this paper, it is important to note that today 1,375 health centers care for $24.3 \mathrm{~m}$ people ( 1 in 13 people in the U.S.; 1 in 10 whom are children) who are disproportionately low income, members of racial and ethnic minority groups, publicly insured or underinsured and likely to be experiencing one or more chronic illnesses. In 2015, 6,906 NPs delivered $27 \%$ of all medical visits in health centers. ${ }^{[24]}$ CHCI established in 1972, was founded by community activists as a free clinic with a commitment to health care as a right, not a privilege. CHCI's first service was dentistry in a 2nd floor walk-up apartment and grew from a single service free clinic to a statewide enterprise serving more than 130,000 active patients from its network of comprehensive primary care hubs, school based health centers, and homeless shelter clinics. ${ }^{[25]}$ CHCI's Weitzman Institute leads the organization's quality improvement, research, and innovations work, including development of the FQHC-based postgraduate training model. ${ }^{[26]}$

\subsection{Purpose}

As more postgraduate NP training programs develop, and the recommendation of the IOM's "Future of Nursing" report ${ }^{[10]}$ to create such programs is more broadly implemented, it is timely to investigate the actual experience of the individuals who choose, are accepted into, and live through and complete such programs. A small number of studies have investigated different dimensions of the experience and outcomes. ${ }^{[9,15,27]}$

Published by Sciedu Press
In order to help new NPs transition from entry-level competence to a level of confidence and competence associated with mastery and well-being as defined by Meleis et al., ${ }^{[28]}$ it is critical to examine this experience. Future development of such programs should be able to build upon a deep understanding of how new NPs experience each individual element and the overall NP residency program - the timing, critical milestones, and facilitating/inhibiting factors that influence both role transition and the development of increased competency and confidence. Thus the purpose of this study was to further our understanding of the experience of the Residents in CHCI's NP residency program, as they transitioned from new NPs to more experienced NPs in the role of PCPs in an FQHC, to identify dominant common themes throughout the year, and to extract key facilitators or inhibitors of a successful transition that either led to or deterred from their sense of mastery and well-being.

\section{Methods}

We used Krippendorffs' content analysis, a qualitative methodology for forming accurate and reproducible inferences from texts and other sources (e.g., recorded speech, cultural artifacts, etc.) within a specific context. ${ }^{[29]}$ Using content analysis, researchers aim to recognize and identify contextual meanings from related sources. The Institutional Review Boards of CHCI and the University of Wyoming approved this study and our intent to review journals submitted by five cohorts of Residents starting with the 2008-2009 cohort and ending with the 2012-2013 cohort. We analyzed de-identified journals from 24 Residents $(100 \%$ of the possible subjects) who submitted a total of 1,200 reflective journal entries.

Journal analysis was done chronologically, by Resident, from the initial entry in September through the final entry submitted at the time of residency graduation in late August. Specifically, we sought to identify key themes as the Residents' experienced the residency. We then considered these themes in terms of the key factors that were either challenging or particularly difficult or stressful for the Residents, as well as factors that supported the Residents in meeting those challenges and in mitigating the stress associated with them.

To establish interrater reliability, we analyzed the first four Residents' journals independently of each other, then compared our identification of key themes and found very strong congruence. The few areas of incongruence were minor (e.g., authors using different terms for similar themes). These areas were then discussed by the authors until agreement was obtained. Subsequently, we independently analyzed journal entries of each Resident, sorted by cohort. Each Resident was assigned a number between 1-24, with one author as- 
signed to all odd numbered Residents' journals and the other author assigned to all even numbered Residents' journals. We reviewed every line of text from our assigned journals and extracted key themes by month for each Resident. We then went through a process of comparing the themes by month, with each researcher identifying approximately ten major themes per month. The researchers met regularly over a period of several months to identify areas of congruence and look for areas of non-congruence, which we did not identify. We then merged the Residents' themes into a single theme table, by month, for all the Residents and collaboratively worked to further reduce the total number of themes to the five most strongly representative themes. Lastly, we analyzed the "final reflective journal" submitted by each Resident, for which they received instructions to write an entry summarizing their experience of the entire residency.

\section{Results}

\subsection{Demographics}

We contacted each of the 24 Residents who completed the residency between 2009 and 2013 and secured written informed consent allowing analysis of their journals. All subjects were female, ranged in age from $24-51$ years $(m=30$ years $)$, had completed the master's degree in nursing less than 18 months prior to starting the residency, and secured board certification as a FNP no later than one month after starting the residency. The Residents had zero to six years of nursing experience prior to the residency, with an average of two years; eight of them had no prior experience working as RNs, and one had practiced as an NP for one year.

\subsection{Journal analysis}

We found strong consistency across key monthly themes experienced by the Residents and equally remarkable consistency in their progression as they moved forward throughout the year. Table 1 contains a selection of quotations that exemplify various themes. Figure 1 provides a month-by-month, chronologic ordering of the major themes that surfaced across the journals of all 24 Residents, which we then coalesced into dominant quarterly themes. Figure 2 considers the data from the perspective of a wheel, representing the 12-month calendar with the outer wheel containing a key, dominant, single theme from each month mutually agreed upon by each researcher. The middle wheel contains seven themes that were identified as critical factors for facilitating the Residents' transition (e.g., on-call experiences and support from preceptors, staff, and co-Residents). At the core of the wheel are nine themes that were identified as persistent throughout the entire residency experience, appearing regularly and irregularly throughout all journals over the course of the residency and viewed as facilitative (e.g., building a panel of patients) or stress-inducing (e.g., managing chronic pain) factors influencing the transition, ${ }^{[28]}$ as the individual moves through a transition to a successful outcome as indicated by mastery and sense of wellbeing.

\subsubsection{First quarter (Sept-Nov): From euphoria to shock and awe}

Although the first month is characterized by euphoria and gratitude for the opportunity to be in the residency, the euphoria is tinged with a harbinger of recognition of just how complicated the patients are likely to be, the intensity of the workload, the impact of social and environmental factors on the health of their patients, and the limits of what primary care and PCPs can do to mitigate them. In addition, the Residents express significant concern about their readiness to care for such patients, coupled with relief that they will have the support of the residency in doing so.

As the Residents begin to see new patients in the second month, presenting for their initial visits with multiple undifferentiated concerns and pent-up demand for health care, the initial euphoria is replaced by the "shock and awe" of just how sick people seen in FQHC primary care can be. Specifically, the Residents expressed shock regarding the magnitude of the impact of behavioral health, trauma, poverty and substance abuse on the lives, health, and healthcare of patients and the demands this places on PCPs and the entire team. Additionally, they were awed by the complexity of the health care system both within CHCI and the larger health neighborhood. The particular challenge of new patients who present with a chief complaint of pain and an apparent priority focus on securing opioid medication was a major stressor that appeared right at the beginning, and persisted throughout the year. The intensity of the distress experienced by the Residents in assessing, responding to, and managing patients with chronic pain was mitigated, though never fully eliminated, by the consistent support of preceptors and the organization's well-developed policies in this domain.

\subsubsection{Second quarter (Dec-Feb): From exhaustion to heads above water}

By the second quarter, themes of exhaustion, astonishment at how hard the work of a PCP is, and real pleasure in the knowledge and skills being gained through didactics and specialty rotations emerge. These are accompanied by a flickering sense of increasing feelings of competence and confidence, expanding to a sense that their "heads are above water" by February, as they begin to reap the satisfaction and joy of managing their "own" panel of patients, witnessing the improvements their patients are making on multiple fronts, and appreciating the resources available in an integrated primary care system and particularly, the ready availability of 
behavioral health services.

\subsubsection{Third quarter (March-May): Managing complexity to awareness of emerging competency}

The third quarter reflects the focus on timed acceleration of the scheduling of patient visits and more focus on efficiency as their panels grow. The Residents are challenged to develop greater ease in managing the episodic, acute, and chronic problems that present in any busy primary care practice. In addition, we identified a persistent expression of sadness at the impact of trauma, poverty, and stress on individuals and families, especially those with children.

The third quarter also brings an awareness and focus on the future, and next career steps in particular as they begin to seek out their next positions. Throughout each of these three quarters, the journals illuminate "sparks" of energy, professional satisfaction and learning that come with what we have termed "special events" of the residency year, in which the day-to-day of primary care practice is set aside to focus on big picture, community building, or professional development activities. Examples of these include participation in the annual volunteer "mission" events, professional staff dinners, legislative events, professional forums, and even their own presentations at conferences. The journals also reveal a strong personal, professional, and social bond amongst the Residents and their anticipation of a lifelong connection to one another.

Table 1. Example quotations from reflective journals

\begin{tabular}{|c|c|}
\hline Theme & Example quotation \\
\hline Fluctuating competence & "I fluctuate between feeling overwhelmed and relieved. Overwhelmed because the majority of the patients \\
\hline Feeling Inadequate & $\begin{array}{l}\text { "As we shadowed__ a feeling of inadequacy crept up on me. I witnessed all the skills involved in being } \\
\text { a primary care provider for these patients. Ease with cruising through eCw (electronic health record), } \\
\text { clinical knowledge, interpersonal skills, assertiveness and flexibility are some that I can think of right now } \\
\text { among others." }\end{array}$ \\
\hline $\begin{array}{l}\text { Continued astonishment at depth of } \\
\text { poverty, trauma, depression, and } \\
\text { addiction }\end{array}$ & $\begin{array}{l}\text { "I started my child and adolescent psychiatry rotation this week, and it brought up a lot of emotions for me. } \\
\text { Many of the children we saw had been through terrible things - broken homes, abuse, substance abuse by } \\
\text { their parents, etc. I spent a lot of the day wondering how much of the medication that was prescribed was } \\
\text { treating conditions created (or at least drastically worsened) by stress and dysfunction. What should we } \\
\text { think as a society about the fact that we're treating conditions triggered in many ways by poverty?" }\end{array}$ \\
\hline Work-life balance issues & $\begin{array}{l}\text { "It's easy for this job to swallow one's life....I want to have a life outside of my job; have my own family one } \\
\text { day and have healthy relationships within this family, have time to go my son/daughter's soccer game on a } \\
\text { Saturday, etc., etc... How will I balance my obligations as a provider while attending to my family members } \\
\text { and to my own health?" }\end{array}$ \\
\hline Learning to trust self and judgment & $\begin{array}{l}\text { "The residency has been working its magic. I feel able to make reasonable decisions and then trust them -I } \\
\text { spend less time worrying over the weekend about what I've done. I find myself able to give patients good } \\
\text { explanations in response to their questions because I really understand what's happening with their health. } \\
\text { My patients seem trusting of me lately in a way they weren't before - I think they can sense my increased } \\
\text { confidence too. It's exciting to be starting to feel less like an imposter and more like a real PCP, even if I'm } \\
\text { still new and green." }\end{array}$ \\
\hline How far we've come & $\begin{array}{l}\text { "Change has almost snuck up on us---now we want the hard patients, the challenging labs-what a } \\
\text { difference." }\end{array}$ \\
\hline Comfort w & $\begin{array}{l}\text { "Slowly over the past year, I discovered a firm footing in this work, that I am capable of practicing at the } \\
\text { height of my scope as an FNP, that the challenges are real and can be met, and that I was right.... this is } \\
\text { how I want to be, how I can and will be an advocate for the peace and health of everyone." }\end{array}$ \\
\hline $\begin{array}{l}\text { Commitment to primary care for the } \\
\text { underserved }\end{array}$ & $\begin{array}{l}\text { "Hepatitis C is no longer a bullet point on a Power Point slide; it is a middle aged man who won't have sex } \\
\text { because he's afraid of giving someone a death sentence, because he knows he has a death sentence himself. } \\
\text { Anxiety is no longer a vague and very long chapter in a textbook; it is a woman who doesn't work, who } \\
\text { struggles for breath, who knits when she's anxious, and knits something for me. - These are the people I } \\
\text { want to work with." }\end{array}$ \\
\hline Anticipating the future & $\begin{array}{l}\text { "To my utter amazement, I feel ready for the residency to end. I want to move on, to take on a full schedule } \\
\text { with all my own patients, and I feel ready for less supervision. I definitely still want and need help on tricky } \\
\text { cases and I'll need to keep reading at a steady pace to expand my knowledge, but I've developed my own } \\
\text { style as a provider and look forward to getting to work." }\end{array}$ \\
\hline No easy answers in primary care & $\begin{array}{l}\text { "Truth is, it is in large part a gain in confidence, in knowing that you can make an educated guess, handle } \\
\text { the situation, get more in formation and have a patient come back. It is learning there is no perfect answer } \\
\text { to most situations but rather a preferred approach. This is what the residency has been so good-at } \\
\text { providing." }\end{array}$ \\
\hline
\end{tabular}




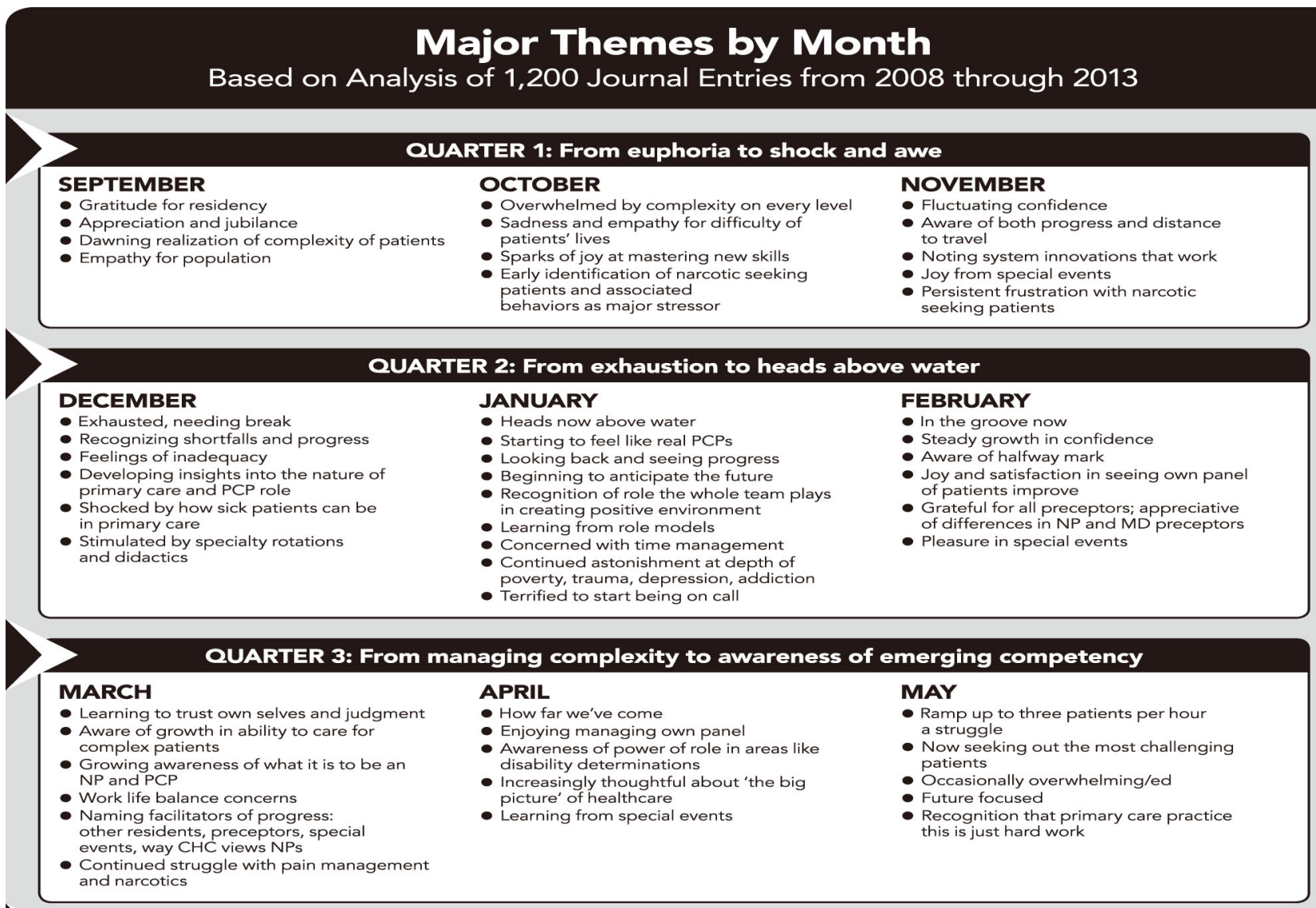

\begin{tabular}{|c|c|}
\hline $\begin{array}{l}\text { JUNE } \\
\text { - Transformation and satisfaction } \\
\text { - Awareness of how critical behavioral } \\
\text { - Wealth is to primary care } \\
\text { - Working on balance of time and quality } \\
\text { of work and life } \\
\text { Gratitude and appreciation for } \\
\text { the residency }\end{array}$ & $\begin{array}{l}\text { JULY } \\
\text { - What was once overwhelming is now } \\
\text { just a busy day } \\
\text { - Aware of deep internal change in } \\
\text { thinking, pattern recognition } \\
\text { - Offering critical feedback on residency } \\
\text { and opportunities for improverement } \\
\text { - Disbelief, anxiety, and gratitude } \\
\text { - We've come a long way } \\
\text { - Focused on their next positions }\end{array}$ \\
\hline \multicolumn{2}{|c|}{ FINAL THEMES } \\
\hline \multicolumn{2}{|c|}{$\begin{array}{l}\text { - Sense of being transformed from into a confident primary care provider who can } \\
\text { cope with the challenges } \\
\text { - Deep appreciation for the residency program, the preceptors, and each other } \\
\text { - Caring for one's own panel of patients has been a critical aspect of the Residency } \\
\text { - There are no easy answers in primary care, focus on a preferred approach } \\
\text { - Ready to move on }\end{array}$} \\
\hline
\end{tabular}

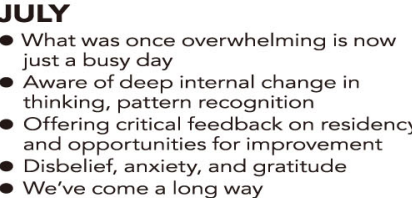

What was once overwhelming is now

just a busy day

- Winking peep in rernal change in

Offering critical feedback on residency

and opportunities for improvement

Disbelief, anxiety, and gratitude

a long way

\section{FINAL THEMES}

Sense of being transformed from into a confident primary care provider who can

- Caring for one's own panel of patients has been a critical aspect of the Residency

- Ready to move on

Figure 1. Major themes by month

\subsubsection{Fourth quarter (June-Aug): Comfort with NP role and commitment to primary care for the under- served and anticipating the future}

The last quarter brings Residents full circle. Quotes like, "What was once overwhelming is now just a busy day" and "Patients so complicated I would have run away from them at the beginning, I now run towards" dominate the journals but are balanced by a very sober consideration of what work life balance issues are in store for them. The program's commitment to get them to an "average" PCP schedule of three patients per hour, of now mostly established patients, is experienced by almost all of them as very difficult. There is evidence of gradual adaptation and a pronounced sense of satisfaction as they "ramp up" to meet the demands of a "real provider", but also a sense of "wishing health care was different, without the pressures of time". With their next position generally confirmed for most of them, themes shift to anticipation of the future and appreciation of how substantially they have met their goals for this residency year.

\subsubsection{Final reflections: Coming full circle}

In addition to the weekly journals, each Resident was asked to complete a final journal reflecting on the entire residency 
year and encouraged to share highs and lows, recommendations for improvements, and insights into those elements that were unsatisfying from a personal goal perspective. The strongest thematic recommendation for improvement was assigning dedicated support staff (MAs, RN) to the Residents. Many individual suggestions for improvement are offered, as captured in Figure 1. The dominant theme was one of having come "full circle" and a sense of completion, tempered by the realization that there is no "knowing" of all there is to know in primary care, They explicitly recognize that they are still at the beginning of their careers, but they are ready to move on as PCPs seasoned by and grateful for the residency experience, and confident in their ability to meet the needs of their patients, as well as their own needs for balance and professional satisfaction.

\section{A Year in the Nurse Practioner Residency Program}

Based on Analysis of 1,200 Journal Entries from 2008 through 2013

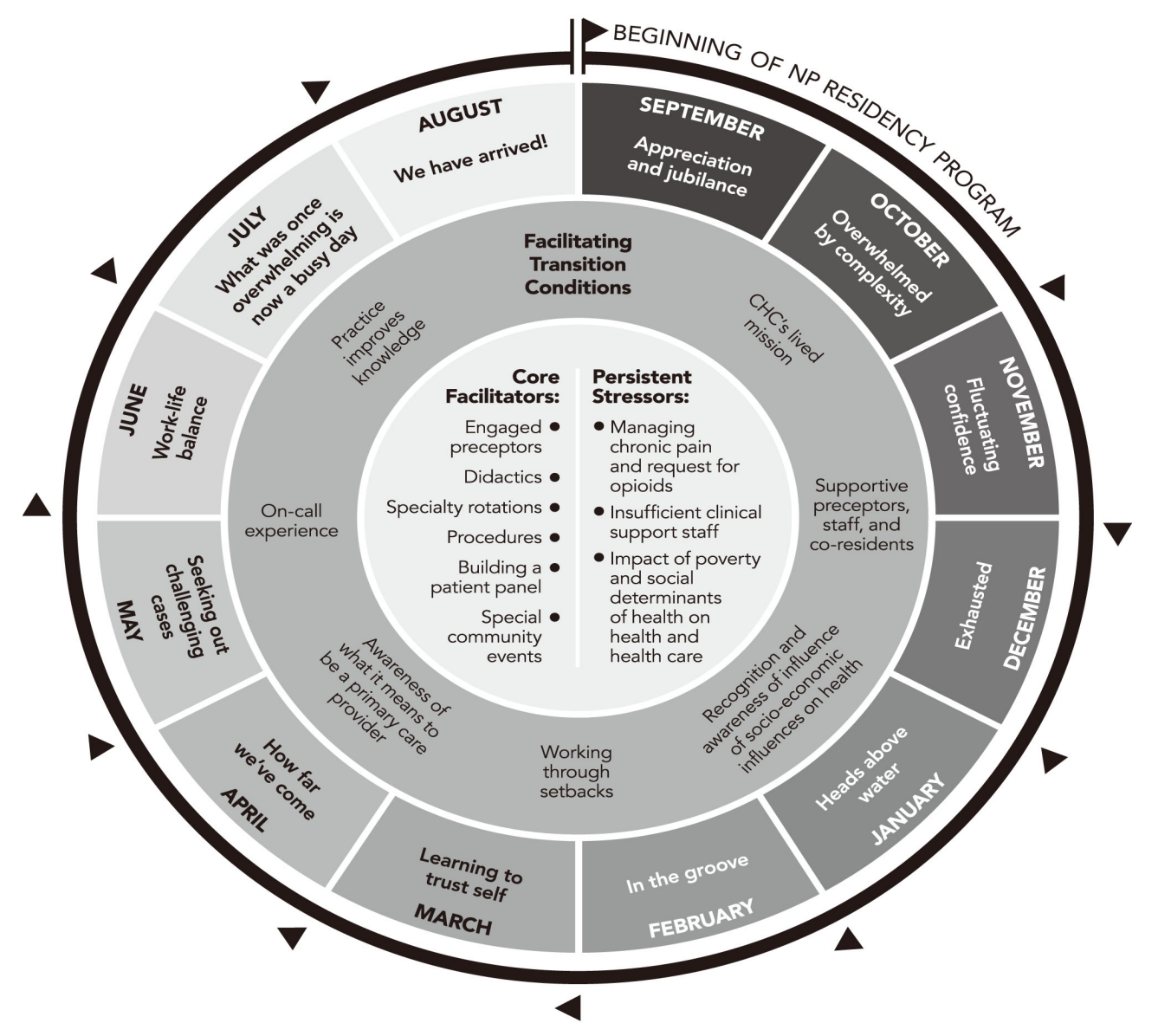

Figure 2. Major themes by month

\section{DiscuSSION}

\subsection{Transition literature}

Our findings point to several areas that are worthy of discussion: transition theory, skill acquisition, reflective practice, and deliberate practice. We also offer implications related to policy, primary care practice, and evaluating post-graduate NP residency and fellowship programs.

Although our study represents the first analysis of the experience of NP Residents, its findings both support and add to the professional role transitioning literature, especially the Published by Sciedu Press transitioning experience of new NPs in a formal postgraduate training program. Our findings support Meleis et al.'s transition theory, which provides a conceptual framework for individuals who are experiencing various life transitions and includes types and patterns of transitions, facilitators and inhibitors to transitioning, and indicators of transitioning. ${ }^{[28]}$ The Residents experienced multiple, simultaneous transitions that are supported by the theory: 1) a developmental transition, as they progressed in competence and confidence; 2) a situational transition, as they joined and progressively contributed to a team of providers and panel of patients at 
a particular $\mathrm{CHCI}$ site; 3) an organizational transition, as they experienced $\mathrm{CHCI}$ addressing and responding to the needs and challenges of the community and state; and 4) a health/illness transition, as they adapted to the stress of maintaining work-life balance. The Residents also experienced multiple aspects associated with Meleis et al.'s transition theory, including an acute awareness of the transition experience; an engagement in the transition process; and a change in focus from specific patient-care guidelines to broader care approaches, while simultaneously being keenly aware of this difference in perspective and a particular timeframe for transition (September-August) with identified critical points (quarters). Figure 2 displays key facilitating transition conditions of the Residents' transition (e.g., CHCI's lived mission and on-call experience), core facilitators (e.g., engaged preceptors and special community events), as well as "persistent stressors" (e.g., managing chronic pain), a term we chose over Meleis et al.'s "inhibitors", as these stressors clearly challenged the Residents but without a sense of inhibition. Interestingly, our analysis did not identify inhibitors to the Residents' transition.

Our findings also fit well with Dreyfus' and Dreyfus' fivestage model of adult skill acquisition, ${ }^{[30,31]}$ which posits that as adults are learning a new skill or profession, they move through five predictable stages, ranging from the novice, who has no experience, to the expert, who has years of experience and relies on intuition, rather than strict rules or maxims, to guide his or her work. In between the extremes of novice and expert, the model proposes three intermediate phases: advanced beginner, the individual with some experience, whose perspective is limited by personal experiences or to experiences pointed out by others; competence, someone who has learned to identify what is important in a particular situation and has developed guidelines to help achieve desired goals; and proficiency, referring to the stage where the individual views situations holistically, perceives deviations from normal patterns, and employs guiding maxims versus strict rules.

Benner's work on professional development in $\mathrm{RNs}^{[32-34]}$ supported Dreyfus' and Dreyfus'mode ${ }^{[30,31]}$ and specified how the model is exemplified in nursing. For example, Benner established how new graduate RNs are usually in the advanced beginner stage and reach the competent stage within one to two years of practice. Furthermore, Benner found that not all RNs reach the proficient or expert stage; however, those who do, go beyond their formal education and practice experience and seemingly make a "qualitative leap" in how they approach their work-a leap that allows them to see the larger context of the situation, beyond the immediate needs of the patient. Although Benner has not studied NPs, her description of the stages of nursing expertise capture the Residents' progression. The Residents entered the residency as Advanced Beginners and brought the experiences they had encountered in their formal NP education. Over the next two quarters, they struggled as they dealt with the idiosyncrasies of a new work setting, the enormity of the PCP role, the variety of diagnoses and presentations encountered in primary care, and the complexity of patients seen at CHCI. However by the second quarter, the Residents have achieved a level of "competence". From the knowledge gained from preceptors, the literature, and didactics, they could now provide an acceptable level of care to patients without the energy and effort required in the first five months; however, new patient presentations and situations continued to challenge and exhaust them. Over the final two quarters, the Residents showed evidence of progressing toward "proficiency", as evidenced that by the end of the residency, they were all able to comfortably shift their focus away from specific patient diagnoses and presentations, toward larger contexts and feel comfortable in how they handled most patient-care situations, even when they were uncertain regarding the specific diagnosis or management plan.

Specific to the NP transition literature, our findings lend some support to Barnes' concept analysis of NP role transition, which represents the most comprehensive study of NP role transition to date, culminating in the following conceptual definition: ${ }^{[35]}$

"NP role transition is a process consisting of multiple mixed emotions that occurs over time, and is a period of great personal development and learning as the NP takes on new autonomy and responsibility for patients. This process occurs as the new NP moves out of the $\mathrm{RN}$ role and absorbs the NP role, and is affected by personal and environmental antecedents, which can lead to a successful or unsuccessful role transition.” (p.142)

Barnes further identified five personal antecedents to NP role transition: 1) graduate-level education, 2) experience (prior nursing or work-life experience), 3) disengagement (to prior role), 4) engagement (in transition experience), and 5) desire for feedback, as well as three environmental antecedents: 1) job novelty (with higher job novelty resulting in increased learning and development), 2) support (from peers, colleagues, mentors, preceptors, and other NPs), and 3) formal orientation.

Regarding Barnes' conceptual definition of NP role transition. ${ }^{[35]}$ our findings reflect that the Residents experienced multiple, mixed emotions as they progressed through the year. Although the residency did not specifically address their emotions, we hypothesize that the act of reflective journaling and 
interacting with other Residents may have facilitated their working through these emotions. Our findings also support Barnes' antecedents of engagement, desire for feedback, job novelty, support, and formal orientation; however, we did not uncover thematic units similar to the antecedents of experience and disengagement, which may reflect that most of the Residents we studied did not have long careers in nursing prior to the residency and may have entered nursing with the intent of eventually becoming an NP. Interestingly, when Barnes $^{[4]}$ examined the relationship between prior nursing experience and formal orientation on NP role transition in 352 NPs, only formal orientation, not nursing experience, was found to correlate with successful NP transition.

\subsection{Reflective practice}

Although not a thematic unit in our analysis, the process of reflective journaling may have also contributed to the Residents' successful transition experiences. In essence, the Residents were engaging in Schon's "reflection-on-action", a critical, self-directed process that challenges one's own beliefs, attitudes, and values that often results in deep, meaningful learning and promotes successful professional transitioning. ${ }^{[36]}$ Along with "reflection-in-action", Schon described "reflection-on-action" as the core of professional practice, and reflective practice (both reflecting "in" and "on" practice) is widely considered a core component of professionalism and a facilitator in successful professional transitioning. ${ }^{[37-39]}$ Reflective practice in the form of weekly reflective journaling was a required component of the $\mathrm{CHCI}$ residency model. Although the impact of this journaling cannot be elucidated from this study, it may have contributed to the Residents' successful transition experience.

\subsection{Deliberate practice}

Similar to reflective practice, our findings support Ericsson's deliberate practice approach, a newer empirically based idea that is gaining ground as a likely path for developing expertise in health-related fields. ${ }^{[40,41]}$ This approach is similar to the expert-performance approach used in music, dance, sports, and chess, where the performer identifies a superior, reproducible performance and deliberately works over a period of years to capture and repeatedly reproduce aspects of this performance until the whole is perfected and consistently reproduced. ${ }^{[42]}$ However unlike music, dance, sports, and chess, the desired outcomes associated with health care, especially primary care, are contingent upon an unlimited number of factors external to the provider (e.g., resources, team members, individual patient and family members, etc.). Thus in many respects, deliberate practice is more appropriate to primary care than expert-performance. In deliberate practice, training activities are designed to improve specific

Published by Sciedu Press aspects of an individual's performance through repetition and successive refinement. However in order to be successful, the learner must deliberately engage in the process, e.g., read, practice, self-monitor, self-reflect, and both seek out and respond to feedback. ${ }^{[40,41]}$

Considering our findings from Ericsson's deliberate-practice approach ${ }^{[40,41]}$ it is not surprising that the final quarter of the Residents' journals showed confidence, competence, and comfort with the primary care provider role, as their journal entries throughout the residency demonstrated that they were actively working (i.e., deliberately practicing) to get the most out of the 12-month residency experience, from continued intensive study to on-going self-reflection. As mentioned previously, the fact that reflective journaling was built into the residency experience likely contributed significantly to the Residents' transitioning and may have facilitated deliberatepractice.

\subsection{Policy implications}

The IOM's "Future of Nursing" report called for residency training for all new NPs in the U.S. and for NPs changing practice areas. ${ }^{[10]}$ It stopped short of addressing critical policy issues such a federal funding, accreditation, developing national capacity to offer residency to all new NPs , and policy implications for the U.S.'s established graduate medical education (GME) legislation. The same committee released a five-year report on progress towards implementation of their recommendations in December, 2015 and again called for postgraduate residency transition to practice programs for APRNs along with a call for more research on the most effective model, and both federal and private funding of such programs. ${ }^{[43]}$ Our work confirms that the IOM recommendation is both timely and appropriate as a major advance forward in providing new NPs with the intensive postgraduate training they deserve for the challenging careers they have chosen. We also recognize that there is on-going discussion about the use of the term "residency", as called for by the IOM Future of Nursing report, ${ }^{[10]}$ versus fellowship, as called for by the U.S.'s multi-organizational Nurse Practitioner Roundtable. ${ }^{[44]}$

There are several policy considerations related to further development and funding. Currently, there is no designated federal support for such programs. Federal graduate medical education (GME) funding in the U.S. is not currently available for postgraduate residency or fellowship training for NPs. GME itself has been the subject of an IOM committee calling for the creation of a transformation fund to study new approaches to GME. ${ }^{[45]}$ Section 5316 of the U.S. Patient Protection and Affordable Care Act, authorized but did not appropriate funding for $\mathrm{FQHC}$ and other safety net 
setting-based NP residency training programs and expired in 2015. ${ }^{[46]}$ The Teaching Health Center legislation was significantly underfunded upon its reauthorization in 2015, and does not allow funding of postgraduate NP residencies in the current statutory language. ${ }^{[47]}$ Accreditation, with its focus on rigor and standardization, has moved forward and is now an option for postgraduate NP training programs, both residency and fellowship. ${ }^{[48]}$ The capacity issue - how to plan and launch enough programs to offer all new NPs who seeks residency the opportunity to participate in one - remains a real one.

\subsection{Limitations}

Several limitations should be considered when interpreting this study. First, the Residents were aware that their journals were being read by a member of CHCI's leadership team, which may have impacted the content of their entries. Second, one of the authors is a leader at CHCI; she personally knew the Residents and responded to many of their journals as they were going through the program. To address this, the journals were de-identified prior our analysis. At least twelve months and up to sixty months had passed since the journals had initially been read. In addition, we established inter-rater reliability by separately analyzing and comparing codes from four journals. Lastly, the study was conducted with Residents who had completed the post-graduate NP residency program at CHCI and might not reflect the experiences of Residents at other NP residency or fellowship programs.

\section{Conclusion}

Although there is significant literature about the challenging nature of the first year of practice for new NPs, most of this was written prior to the development of the postgraduate training experience model. This is the first analysis of the real-time experience of the early participants in this model, specific to the role of primary care provider in FQHCs. Our findings highlight the importance of supporting new NPs in their transition from excellent education and entry-level competency, to competent and confident primary care providers ready to practice as PCPs in the most challenging settings such as FQHCs. Given the critical nature of recruiting and retaining an expert primary care workforce, and the immense value that NPs bring to primary care, it should be a national priority to provide such postgraduate training and support for new NPs. We suggest that this is likely to position new NPs for professional and personal success, and retention as primary care providers, as leaders, and as expert preceptors for the generations of aspiring NPs who follow them.

Our findings also suggest specific areas that warrant attention from NP educators, employers, and researchers in primary care. These include managing the challenges of behavioral health, addiction and trauma in primary care; managing acute and chronic pain; and assessing and responding to the impact of the social determinants of health in primary care. These factors: clinical and systemic complexity, poverty and low literacy, behavioral health and substance abuse issues, and the challenge of managing chronic pain, opioid use, and requests for controlled substances are part of the daily fabric of life as a PCP in a FQHC and represent enormous stress for new NP in the residency. In fact, the experience of the NP Residents in addressing some of these very complex issues is shared by even experienced PCPs and has led CHCI to develop major new supports for all PCPs and their teams through participation in several Project ECHO-CT, an ongoing case-based distance learning intervention to address high complexity health problems, originally developed at the University of New Mexico (U.S.), ${ }^{[4]}$ and now led by a number of organizations, including $\mathrm{CHCI} .{ }^{[50,51]}$

The stress and intensive workload of primary care practice and the life of a primary care provider is sobering, but witnessing and working with providers who maintain their sense of humor, commitment, and professional satisfaction is a critical offset. The Residents' observations of the importance of the health care team in having a satisfying work experience are compelling and strongly support the movement towards team-based care, including fully integrated behavioral health.

Finally, we ask two critical questions. First, do the outcome measures of a successful transition, as evidenced by the Residents' sense of increased competence, confidence, mastery and sense of wellbeing, lead to sustained, satisfying careers as primary care providers and in particular, the safety net? CHCI's internal data tracking of all 46 of the NPs who have completed the residency as of 2015 confirms that $91 \%$ are practicing as primary care providers, and $86 \%$ are practicing in FQHCs. Although data from a recent study indicate that postgraduate NP education is associated with higher job satisfaction, ${ }^{[52]}$ we do not know whether or how our study's outcomes factor into job satisfaction. Second, can we measure the NP Residents' progress objectively, particularly in terms of competency assessment? This study focused entirely on the written reflections of the NP Residents about their experience. Other data, including frequent performance appraisals submitted by preceptors and program leaders relative to the learning objectives assigned to each element of the program were not included in the scope of this study. Fortunately, recent literature has called for the need to develop standard evaluation tools for NP residencies. ${ }^{[53]}$ Over the past several years, other postgraduate NP training programs, particularly within the U.S. Veteran Affairs (VA) Centers of Excellence, have focused on developing robust 
competency assessment tools. ${ }^{[54]}$ Implementing the use of such a tool, and studying outcomes among and between programs is a high priority in the further development of our knowledge about postgraduate NP training. Further study, with inclusion of other postgraduate NP training programs across the U.S., would be of significant value in determining if the investment of resources on the part of new NPs, the organizations hosting the NP residency, and potential national investments are duly warranted. Our findings suggest

\section{REFERENCES}

[1] Newhouse RP, Stanik-Hutt J, White KM, et al. Advanced practice nurse outcomes 1990-2008: a systematic review. Nurs Econ. 2011 Sep-Oct; 29(5): 230-50. PMid:22372080

[2] Stanik-Hutt J, Newhouse RP, White KM, et al. The quality and effectiveness of care provided by nurse practitioners. J Nurs Pract. 2013 Sep; 9(8): 492-500; e1-13. http://dx.doi.org/10.1016/j.nur pra. 2013.07.004

[3] Swan M, Ferguson S, Chang A, et al. Quality of primary care by advanced practice nurses: a systematic review. Int J Qual Health Care. 2015 Oct; 27(5): 396-404. http: //dx.doi.org/10.1093/intqh $\mathrm{c} / \mathrm{mzv} 054$

[4] Barnes H. Exploring the factors that influence nurse practitioner role transition. J Nurse Pract. 2015 Feb; 11(2): 178-83. http: //dx.doi.org/10.1016/j.nurpra.2014.11.004

[5] Heitz LJ, Steiner SH, Burman ME. RN to FNP: a qualitative study of role transition. J Nurs Educ. 2004 Sep; 43(9): 416-20. PMid:15478695

[6] Steiner SH, McLaughlin DG, Hyide RS, et al. Role transitioning during RN-to-FNP education. J Nurs Educ. 2008 Oct; 47(10): 441-7. http://dx.doi.org/10.3928/01484834-20081001-07

[7] Flinter M. Residency programs for primary care nurse practitioners in federally qualified health centers: a service perspective. Online J Issues Nurs. 2005 Sep 30; 10(3): 6. PMid:16225386

[8] Hart AM, Macnee CL. How well are NPs prepared for practice: results of a 2004 questionnaire study. J Am Acad Nurse Pract. 2007 Jan; 19(1): 35-42. http://dx.doi.org/10.1111/j.1745-759 9.2006.00191.x

[9] Sargent L, Olmedo M. Supporting the needs of new-graduate nurse practitioners: a model to support transition. J Nurs Adm. 2013 Nov; 43(11): 603-10. http://dx.doi.org/10.1097/01. NNA.000043 $4506.77052 . d 2$

[10] Institute of Medicine. The future of nursing: leading change, advancing health. Washington, DC: National Academies Press; 2011: $1-671$.

[11] Flinter M. From new nurse practitioner to primary care provider: bridging the transition through FQHC-based residency training. Online J Issues Nurs. 2011 Nov 28; 17(1): 6. PMid:22320872

[12] Community Healthcare Network. First nurse practitioner primary care residency program in New York state launches [Internet]. 2015 Feb 27 [cited 2016 June 26]. Available from: http: //www . chnnyc .org/general/first-nurse-practitioner-primary-car e-residency-program-in-new-york-state-launches that they are, but we welcome additional research to further advance our knowledge in this area.

\section{ACKNOWLEDGEMENTS}

The study was partially funded in part by the Sharon S. Humenick Award through the Fay W. Whitney School of Nursing at the University of Wyoming.

\section{CONFLICTS OF INTEREST Disclosure}

The authors declare that there is no conflict of interest.
[13] Sea Mar Community Health Centers. Family Nurse Practitioner Residency [Internet]. 2015 Oct [cited 2016 June 26]. Available from: http://www.seamar.org/fnpr/

[14] Gilman SC, Chokshi DA, Bowen JL, et al. Connecting the dots: Interprofessional health education and delivery system redesign at the Veterans Health Administration. Acad Med. 2014 Aug; 89(8): 1113-6. http://dx.doi.org/10.1097/ACM.0000000000000312

[15] Zapatka S, Conelius J, Edwards J, et al. Pioneering a primary care adult NP interprofessional fellowship. J Nurs Pract. 2014 June; 10(6): 378-386. http://dx.doi.org/10.1097/ACM.000000000 0000312

[16] Carolinas HealthCare System Center, Center for Advanced Practice. Center for advanced Practice fellowship [Internet]. c2016 [cited 2016 June 26]. Available from: http://www.carolinashealthcare. org/center-for-advanced-practice-fellowship

[17] Johns Hopkins Medicine, Nurse practitioner fellowship program [Internet]. [cited 2016 June 26]. Available from: http://www.hopkinsmedicine.org/gastroenterology_h epatology/education_training/nurse_practitioner_fe llowship_program.html

[18] University of Maryland Medical Center. Fellowship program [Internet]. c2016 [2016 June 26]. Available from: http://umm . edu/pr ofessionals/nurse-practitioners/fellowship

[19] Carilion Clinic, Emergency Department Fellowship Information [Internet].Training nurse practitioner and physician assistants at Carilion Clinic in Virginia. c2016 [cited 2016 June 26]. Available from: https://www.carilion.org/emergency-department/ fellowship/np-pa

[20] PR Newswire [Internet]. MinuteClinic recognizes national nurse practitioner week and invests in the education and advancement of clinicians across the U.S. 2012 Nov 13 [cited 2016 June 26] Available from: http://www.prnewswire.com/news-release s/minuteclinic-recognizes-national-nurse-practitio ner-week-and-invests-in-the-education-and-advance ment-of-clinicians-across-the-us-179148671.html

[21] Geiger HJ. Community oriented primary care: a path to community development. Am J Public Health. 2002 Nov; 92(11): 17136. PMid:12406790 http://dx.doi.org/10.2105/AJPH.92.11. 1713

[22] Geiger HJ. The first community health centers: a model of enduring value. J Ambul Care Manage. 2005 Oct-Dec; 28(4): 313-20. PMid:16172560 http://dx.doi.org/10.1097/00004479-200 510000-00006

[23] Lefkowitz B. The health center story: forty years of commitment. J Ambul Care Manage. 2005 Oct-Dec; 28(4): 295-303. 
PMid:16172558 http://dx.doi.org/10.1097/00004479-200 510000-00004

[24] U.S. Department of Health and Human Services, Health Resources Services Administration, 2015 Health Center Program Data [cited 2016 August 30]. Available from: http://bphc.hrsa.gov/uds/ datacenter.aspx

[25] Community Health Center, Inc. [Internet]. 2016 [cited 2016 June 2016].

[26] Weitzman Institute [Internet]. 2016 [cited 2016 June 26]. Available from: http://weitzmaninstitute.org/?utm_source= chc1. com\&utm_medium=banner\&utm_campaign=WIBanner

[27] Flinter M. From new nurse practitioner to primary care provider: a multiple case study of new nurse practitioners who completed a formal post-graduate residency training [dissertation]. [Storrs (CT)] University of Connecticut, 2010.

[28] Meleis AI, Sawyer LM, Im EO, et al. Experiencing transitions: an emerging middle-range theory. Adv Nurs Sci. 2000 Sep; 23(1): 12-28. PMid:10970036 http://dx.doi.org/10.1097/00012272-200 009000-00006

[29] Krippendorff K. Content analysis: an introduction to its methodology (3rd ed.). Los Angeles, CA: Sage; 2013.

[30] Dreyfus SE, Dreyfus HL. A five-stage model of the mental activities involved in directed skill acquisition. Washington, DC: Storming Media, 1980. Available from: https://en.wikipedia.org/wik i/Dreyfus_model_of_skill_acquisition

[31] Dreyfus SE. The five-stage model of adult skill acquisition. Bull Sci Tech Soc. 2004; 24(3): 177-81. http://dx . doi .org/10.1177/0 270467604264992

[32] Benner P. From novice to expert: excellence and power in clinical nursing practice. Menlo Park, CA: Addison-Wesley, 1984 1-307.

[33] Benner P, Tanner CA, Chesla CA. Expertise in nursing practice: caring, clinical judgment, and ethics. 2nd ed. New York, NY: Springer; 2009. 1-497.

[34] Benner P. Using the Dreyfus model of skill acquisition to describe and interpret skill acquisition and clinical judgment in nursing practice and education. Bull Sci Tech Soc. 2004 June; 24(3): 188-99. http://dx.doi.org/10.1177/0270467604265061

[35] Barnes H. Nurse practitioner role transition: a concept analysis. Nurs Forum. 2014 Jul-Sep; 50(3): 137-46. http://dx.doi.org/10.11 $11 /$ nuf . 12078

[36] Schon DA. The reflective practitioner: how professionals think in action. New York, NY. Basic Books. 1983: 1-374.

[37] Bolden L, Cuevas N, Raia L, et al. The use of reflective practice in new graduate registered nurses residency program. Nurs Adm Q. 2011 Apr-Jun; 35(2): 134-9. http://dx.doi.org/10.1097/NAQ .0b013e31820feb5e

[38] Elliott L, Daily NL, Fredericks L, et al. Transitioning from students to professionals: using a writing across the curriculum model to scaffold portfolio development. The Teacher Educator. 2008 Jan-Mar; 43(1): 46-58. http://dx.doi.org/10.1080/08878730701728895

[39] Thompson S, Thompson N. The critically reflective practitioner. New York, NY: Palgrave MacMillan, 2008: 1-183.

[40] Ericsson KA. Deliberate practice and the acquisition and maintenance of expert performance in medicine and related domains.
Acad Med. 2004 Oct; 79(10 Suppl): S70-81. PMid:15383395 http://dx.doi.org/10.1097/00001888-200410001-00022

[41] Ericsson KA. Acquisition and maintenance of medical expertise: a perspective from the expert-performance approach with deliberate practice. Acad Med. 2015 Nov; 90(11): 1471-86. PMid:26375267 http://dx.doi.org/10.1097/ACM.0000000000000939

[42] Ericsson KA, Lehmann AC. Expert and exceptional performance: Evidence of maximal adaptation to task constraints. Annu Rev Psychol. 1996; 47: 273-305. PMid:15012483 http://dx.doi.org/1 0.1146 /annurev.psych.47.1.273

[43] National Academies of Sciences, Engineering and Medicine. Assessing progress on the Institute of Medicine report: the future of nursing Washington, DC: National Academies Press; 2016. 1-202

[44] Nurse Practitioner Roundtable. Nurse Practitioner Perspective on Education and Post-Graduate Training, 2015 May6 [cited 2016 June 26]. Available from: http://c.ymcdn.com/sites/nonpf.site-ym.com/reso urce/resmgr/Docs/NPRoundtableStatementPostGra.pdf

[45] Institute of Medicine. Graduate medical education that meets the nation's health needs. Washington, DC: The National Academies Press; 2014:1-209.

[46] Demonstration grants for family nurse practitioner training programs. Patient Protection Affordable Care Act. 2010.

[47] Chen C, Chen F, Mullan F. Teaching health centers: a new paradigm in graduate medical education. Acad Med. 2012 Dec; 87(12): 1752-6. http://dx.doi.org/10.1097/ACM.0b013e3182720f4d

[48] National Nurse Practitioner Residency \& Fellowship Training Consortium.Accreditation standards. c2015 [cited 2016 June 26]. Available from: http://www.nppostgradtraining.com/Accredi tation-Standards

[49] Arora S, Kalishman S, Thornton K, et al. Expanding access to Hepatitis $\mathrm{C}$ virus treatment - extension for Community Healthcare Outcomes $(\mathrm{ECHO})$ project: disruptive innovation in specialty care. Hepatology. 2010 Sep; 52(3): 1124-33. http://dx.doi.org/10.10 02/hep. 23802

[50] Anderson D, Wang S, Zlateva I. Comprehensive assessment of chronic pain management in primary care: a first phase of a quality improvement initiative at a multi-site community health center. Qual Prim Care. 2012; 20(6): 421-33. PMid:23540822

[51] Khatri K, Haddad M, Anderson D. Project ECHO: Replicating a novel model to enhance access to hepatitis $\mathrm{C}$ care in a community health center. J Health Care Poor Underserved. 2013 May; 24(2): 850-8. http://dx.doi.org/10.1353/hpu. 2013.0093

[52] Bush CT, Lowery B. Postgraduate nurse practitioner education: impact on job satisfaction. J Nurs Pract. 2016 April; 12(4): 226-34. http://dx.doi.org/10.1016/j.nurpra.2015.11.018

[53] Sciacca K, Reville B. Evaluation of nurse practitioners enrolled in fellowship and residency programs: methods and trends. J Nurse Pract. 2016 June; 12(6): e275-80. http://dx.doi.org/10.1016 /j.nurpra.2016.02.011

[54] Rugen KW, Speroff E, Zapatka SA, et al. Veterans Affairs interprofessional nurse practitioner residency in primary care: a competencybased program. J Nurs Pract. 2016 June; 12(6): e267-273. http: //dx.doi.org/10.1016/j.nurpra.2016.02.023 